\title{
Health Literacy and Injury Prevention Behaviors Among Caregivers of Infants
}

\author{
William J. Heerman, MD, Eliana M. Perrin, MD, MPH, H. Shonna Yin, MD, MS, Lee M. \\ Sanders, MD, MPH, Svetlana K. Eden, MS, Ayumi Shintani, PhD, MPH, Tamera Coyne- \\ Beasley, MD, MPH, Andrea B. Bronaugh, BA, Shari L. Barkin, MD MSHS, and Russell L. \\ Rothman, MD, MPP \\ From the Department of Pediatrics (Heerman, Barkin), Department of Biostatistics (Eden, \\ Shintani), and Department of Internal Medicine and Pediatrics and Center for Health Services \\ Research (Bronaugh, Rothman), Vanderbilt University Medical Center, Nashville, Tennessee; \\ Department of Pediatrics and Cecil G. Sheps Center for Health Services Research, University of \\ North Carolina at Chapel Hill School of Medicine (Perrin, Coyne-Beasley), Chapel Hill, North \\ Carolina; Department of Pediatrics, New York University School of Medicine (Yin), New York, \\ New York; and the Department of Pediatrics and Center for Health Policy, Stanford University \\ (Sanders), Stanford, California
}

\section{Abstract \\ Background-Unintentional injury is a leading cause of infant mortality. \\ Purpose-To examine the role of caregiver health literacy in infant injury prevention behaviors. \\ Methods-A cross-sectional analysis of data collected in 2010-2012 from a randomized trial at four pediatric clinics was performed in 2012-2013. Caregiver health literacy was assessed with the Short Test of Functional Health Literacy in Adults. Caregiver-reported adherence to American Academy of Pediatrics-recommended injury prevention behaviors was assessed across seven domains: (1) car seat position; (2) car seat use; (3) sleeping safety; (4) fire safety; (5) hot water safety; (6) fall prevention; and (7) firearm safety.}

Results-Data were analyzed from 844 English and Spanish-speaking caregivers of 2-month-old children. Many caregivers were non-adherent with injury prevention guidelines, regardless of health literacy. Notably, $42.6 \%$ inappropriately placed their children in the prone position to sleep, and $88.6 \%$ did not have their hot water heater set $<120^{\circ} \mathrm{F}$. Eleven percent of caregivers were categorized as having low health literacy. Low caregiver health literacy, compared to adequate

(C) 2014 American Journal of Preventive Medicine. Published by Elsevier Inc. All rights reserved.

Address correspondence to: William Heerman, MD, Vanderbilt University Medical Center, Department of Pediatrics, 2146 Belcourt Ave, 2nd Floor, Nashville TN 37212. Bill.Heerman@ vanderbilt.edu.

Preliminary data from this study were presented at the 2012 Health Literacy Annual Research Conference (HARC), cosponsored by the NIH; October 18, 2012, Bethesda MD.

No financial disclosures were reported by the authors of this paper.

Publisher's Disclaimer: This is a PDF file of an unedited manuscript that has been accepted for publication. As a service to our customers we are providing this early version of the manuscript. The manuscript will undergo copyediting, typesetting, and review of the resulting proof before it is published in its final citable form. Please note that during the production process errors may be discovered which could affect the content, and all legal disclaimers that apply to the journal pertain. 
health literacy, was significantly associated with increased odds of caregiver non-adherence with recommended behaviors for car seat position ( $\mathrm{AOR}=3.4,95 \% \mathrm{CI}=1.6,7.1)$, and fire safety ( $\mathrm{AOR}=2.0,95 \% \mathrm{CI}=1.02,4.1)$ recommendations. Caregivers with low health literacy were less likely to be non-adherent to fall prevention recommendations ( $\mathrm{AOR}=0.5,95 \% \mathrm{CI}=0.2,0.9)$.

Conclusions-Non-adherence to injury prevention guidelines was common. Low caregiver health literacy was significantly associated with some injury prevention behaviors. Future interventions should consider the role of health literacy in promoting injury prevention.

\section{Introduction}

Despite well-established prevention strategies, sudden infant death syndrome (SIDS) and unintentional injury remain leading causes of infant mortality in the U.S. According to the CDC, SIDS was the third leading cause of infant mortality in 2010, accounting for $8.4 \%$ of deaths, and unintentional injury was the fifth leading cause, accounting for $4.5 \%$ of deaths. ${ }^{1}$ In children aged $<1$ year, the leading causes of unintentional injuries are falls, toxic ingestions, motor vehicle crashes, foreign body ingestions, and fire-related injuries, ${ }^{2}$ most of which are thought to be preventable. Moreover, it is often the case that caregiver safety practices do not adhere to well-established injury prevention recommendations. ${ }^{3,4}$

Health literacy can be defined as "the degree to which individuals have the capacity to obtain, process, and understand basic health information and services needed to make appropriate health decisions." ${ }^{5}$ Health literacy includes print literacy (writing and reading skills), oral literacy (listening and speaking skills), numeracy (quantitative skills), and cultural and conceptual knowledge (ways of learning). ${ }^{6}$ Low health literacy affects nearly 80 million U.S. adults, ${ }^{7}$ with nearly $30 \%$ of U.S. caregivers categorized as having below basic or basic health literacy. Caregivers with lower literacy have worse health outcomes, are less likely to understand health information and instructions, ${ }^{7-9}$ and may be less likely to follow recommendations related to preventive behaviors.

Previous studies, however, have not directly investigated the role of caregiver health literacy on adherence to pediatric injury prevention recommendations. Therefore, the aim of this study is to investigate the effect of health literacy on the likelihood of caregiver adherence to injury prevention guidelines. We hypothesize that caregivers with low health literacy are less likely to adhere to standard infant injury prevention recommendations.

\section{Methods}

A cross-sectional analysis of baseline data was performed on data collected from caregiverchild pairs participating in the Greenlight study. The Greenlight study is a clusterrandomized trial of a low-literacy sensitive health communication intervention to reduce obesogenic behaviors and prevent obesity in the first 2 years of life. The study was conducted at pediatric resident primary care clinics that predominantly care for underserved populations. In the study, two sites were randomized to receive pediatric resident training in health communication skills and a Greenlight toolkit of educational materials aimed at obesity prevention to be used at each well-child visit from age 2 months to 2 years. The other two study sites were attention control sites, where residents received injury prevention 
training and used educational materials from the American Academy of Pediatrics' (AAP) The Injury Prevention Program (TIPP) ${ }^{10}$ at each well-child visit from age 2 months to 2 years. Data for this analysis were collected at baseline, before participants would have been exposed to the intervention.

Consecutive eligible caregiver-child pairs were enrolled from the four following universityaffiliated pediatric continuity clinics: (1) New York University (NYU)/Bellevue Hospital Center; (2) Vanderbilt University; (3) University of North Carolina-Chapel Hill (UNC); and (4) University of Miami/Jackson Memorial Medical Center. Enrollment occurred between April 28, 2010 and August 30, 2012. Inclusion criteria for caregiver-child pairs were: (1) infant aged 6-16 weeks presenting for a 2-month well-child visit with a pediatric resident and (2) a caregiver who spoke English or Spanish, who (3) reported that they planned to return to the clinic for all well-child visits through age 2 years. Child-related exclusion criteria were: (1) <34 weeks gestation; (2) birth weight < 1500 grams; (3) weight-for-length $<3$ rd percentile at 2-month visit; or (4) diagnosis of failure to thrive or other medical problem known to affect child growth (e.g., cleft palate). Caregiver-related exclusion criteria were: (1) age <18 years; (2) significant mental/neurological illness; or (3) poor visual acuity (assessed by Rosenbaum Pocket Screener; worse than 20/50 corrected vision).

Written informed consent was obtained from all participants. IRB approval was obtained from all four participating academic medical centers. Data were obtained by interview at the 2-month well-child visit. Interviews were conducted in English or Spanish, based on caregiver preference. Study data were managed using the secure Research Electronic Data Capture tools (REDCap) hosted at Vanderbilt University. ${ }^{11}$

The primary outcomes of interest were caregiver-reported injury prevention practices. These outcomes were based on AAP and TIPP recommendations and the leading causes of preventable injuries in children, ${ }^{2}$ and were assessed using a questionnaire developed by the Greenlight study team and other national experts in injury prevention. The following outcomes were analyzed: (1) car seat position; (2) car seat use; (3) sleeping safety; (4) fire safety; (5) hot water safety; (6) fall prevention; and (7) firearm safety. The specific questions used to assess these outcomes, and how outcomes were defined, are listed in Table 1. Caregiver responses were coded as either adherent or non-adherent to the recommended guidelines (Table 1).

The primary independent variable for this study was caregiver health literacy, assessed using the Short Test of Functional Health Literacy in Adults (STOFHLA). ${ }^{12}$ The STOFHLA was administered by trained study personnel at baseline data collection performed during the child's 2-month well-child check. Based on previously validated cut-off points, health literacy was categorized as inadequate (score, 0-16), marginal (17-22), or adequate (23-36). The STOFHLA is one of the most commonly used health literacy assessments and has been validated in both English and Spanish. ${ }^{13-16}$ Similar to numerous previous studies, health literacy was dichotomized a priori into adequate health literacy and low (inadequate or marginal) health literacy. ${ }^{7,17-20}$ Demographic characteristics including child age, child gender, caregiver age, caregiver gender, relationship to child (mother, father, or other), race/ ethnicity, caregiver language, education, and household income were summarized using 
mean and SD for continuous variables and using proportions for categorical variables. Race/ ethnicity was categorized as four mutually exclusive categories: (1) Hispanic; (2) nonHispanic, white; (3) non-Hispanic, black; or (4) non-Hispanic, other. Caregiver language was determined by self-report and categorized based on language of study administration.

Data were analyzed in 2012 and 2013. Unadjusted and adjusted associations were assessed between health literacy and the outcomes of interest using logistic regression. To prevent over-fitting, and given the rare occurrence of some outcomes, a limited set of covariates for the adjusted analysis were chosen a priori, including: (1) race/ethnicity; (2) household income; and (3) recruitment site. For these analyses, race/ethnicity was divided into three categories: (1) non-Hispanic, white (reference category) versus (2) Hispanic versus (3) nonHispanic, other. Household income was dichotomized into two categories of $<\$ 20,000 /$ year versus $>\$ 20,000$ /year, and recruitment site was dichotomized into the intervention versus control sites of the Greenlight study. Given potential strong colinearity between education and literacy, and similar to previous studies, the primary model did not include education as a covariate. ${ }^{21,22}$ However, in a secondary analysis, education was included as a dichotomous variable (less than high school graduate versus high school graduate or higher). Data were analyzed using R version 2.15 (www.r-project.org) and Stata version 12.1 (StataCorp LP, College Station TX). For all analyses, a two-tailed $p$-value $<0.05$ was considered statistically significant.

\section{Results}

From April 28, 2010 to August 30, 2012, families presenting with their infant for a 2-month well-child visit were consecutively assessed for possible study participation. A total of 844 families were enrolled and had complete data (Figure 1). Baseline characteristics are presented in Table 2. The mean (SD) age at enrollment for the index child was $2.1(0.4)$ months, and 51.6\% of enrolled children were girls. Mean (SD) caregiver age at enrollment was $27.6(6.2)$ years, and $95.9 \%$ of index caregivers were mothers. Among the enrolled families, $49.8 \%$ self-identified as Hispanic. Among the $32.3 \%$ of families that were categorized as other, non-Hispanic, 230 self-identified as non-Hispanic, black, and 43 selfidentified as non-Hispanic, other. Median caregiver STOFHLA score was 34 (interquartile range $[\mathrm{IQR}]=32,35)$, and $11.0 \%$ were categorized as having low health literacy $(7.8 \%$ inadequate and $3.2 \%$ marginal). The distribution of the number of children in the home did not differ between caregivers with low health literacy and those with adequate health literacy.

The percentage of families not adhering to recommended injury prevention behaviors is summarized in Table 3. Of the 769 caregivers who reported that their child ever rides in a car, $6.6 \%$ used incorrect car seat placement, placing the car seat in the front seat or in the back seat but frontward facing. Of the 835 caregivers who completed the survey, $42.1 \%$ reported ever placing their child in the prone position to sleep in the last 30 days, and $10.4 \%$ reported that their child sleeps prone more than 15 times per month. When asked about fire safety, $6.7 \%$ reported that they did not have a working smoke detector or that they did not know if their smoke detector is working. When asked what the temperature of their hot water heater was, $88.6 \%$ of caregivers reported that it was $>120^{\circ} \mathrm{F}$ or that they did not know 
the temperature. When asked about fall prevention, 23.2\% of caregivers reported that they had left their children unattended on a high surface.

Of the 62 caregivers who reported owning a gun, 59.6\% reported at least one non-adherent behavior: $26.1 \%$ reported that their guns were not locked, $18.5 \%$ reported that their guns were stored loaded, $23.1 \%$ reported that the bullets were not stored separately and locked, and $26.1 \%$ reported that they had at least one gun loaded and ready to use.

The association between caregiver health literacy and non-adherence to injury prevention recommendations is summarized in Table 3. In unadjusted analyses, caregivers with low health literacy had 3.5-fold higher odds of non-adherence to car seat placement (front seat or frontward facing; $\mathrm{OR}=3.5,95 \% \mathrm{CI}=1.8,6.9, p<0.001$ ) and 2.4-fold higher odds of nonadherence to fire safety (no working smoke detector; $\mathrm{OR}=2.4,95 \% \mathrm{CI}=1.2,4.7, p=0.012$ ). Paradoxically, caregivers with low health literacy had nearly twice the odds of adhering to safe fall prevention practices, with a non-adherence OR of 0.4 (95\% CI=0.2, 0.8, $p=0.008$ ). Health literacy status was not associated with regular car seat usage, putting the child to sleep supine, proper hot water heater safety, or firearm safety.

Results of adjusted analyses are also presented in Table 3. Adjusting for race/ethnicity, study site, and household income, caregivers with low health literacy had 3.4-fold higher odds of being non-adherent with car seat placement ( $\mathrm{AOR}=3.4,95 \% \mathrm{CI}=1.6,7.1, p<0.001)$ and 2.0fold higher odds of being non-adherent with fire safety ( $\mathrm{AOR}=2.0,95 \% \mathrm{CI}=1.02,4.1$, $p=0.05$ ). Caregivers with low health literacy had twice the odds of adhering to safe fall prevention practices, with a non-adherence AOR of 0.5 (95\% CI=0.2, 0.9, $p=0.04)$. Similar results were found when caregiver education was added to the model; the AOR for nonadherence to car seat safety was $3.4(95 \% \mathrm{CI}=1.6,7.1, p<0.001)$, that to fire safety was 2.3 ( $95 \% \mathrm{CI}=1.02,4.1, p=0.03)$, and that to fall prevention was 0.5 (95\% $\mathrm{CI}=0.2,0.9, p=0.054)$.

\section{Discussion}

In this study, there was a relationship between caregiver health literacy and some injury prevention behaviors among caregivers of 2-month-old children. Specifically, caregivers with low health literacy were less likely to position their child's car seat correctly and know whether their smoke detector was working. Paradoxically, caregivers with low health literacy were also more likely to practice safe fall prevention. Contrary to the stated hypotheses, there was no association between caregiver health literacy and the other measures of injury prevention behaviors.

A major concern from this study was the high prevalence of reported non-adherence with standard injury prevention behaviors. Some of these results were similar to those reported previously, while other results were different or have not been previously reported in this young patient population. In this study, $7 \%$ of caregivers reported that their infant's car seat was placed incorrectly. It is difficult to compare this finding with other previously reported statistics, as most studies have directly observed car seat placement and noted incorrect installation (even if placed rear facing and in the back seat) up to $85 \%$ of the time. ${ }^{23}$ In this study, $43 \%$ of caregivers reported placing their children prone to sleep, which is somewhat 
lower than previous reports of up to $58 \% .^{24}$ In addition, $60 \%$ of caregivers in this study do not practice firearm safety, which is substantively higher than previously published reports of up to $27 \% .{ }^{25}$ It is difficult to ascertain the reasons for the differences in self-reported behaviors in our study compared to previously published reports. Among the hypothesized reasons are differences in population sociodemographic characteristics and true secular trends in population behaviors. Because unintentional injury remains a leading cause of infant mortality, however, the association between these behaviors and parent health literacy warrants targeted intervention. Translating known risk factors into effective interventions remains a significant challenge. Using data from this study, we would suggest that future injury prevention interventions for car seat use and other injury prevention recommendations should consider low health literacy as an important risk factor. The present data also suggest that interventions should target caregivers of young infants, as non-adherence to injury practices is highly prevalent among caregivers of 2-month-old infants. Identifying caregiver practices at age 2 months gives pediatric providers the opportunity to help caregivers develop safe injury prevention habits before the peak incidence of childhood injury between age 13 and 15 months. $^{2}$

One of the more surprising findings from this study is that caregivers with low health literacy were more likely to practice safe fall prevention. We propose two possible explanations for this finding. First, caregivers with high literacy may be applying ageappropriate developmental milestones (e.g., a 2-month old is typically unable to roll off a bed or high table), relying on their own judgment rather than on recommendations from their pediatrician. Another possibility is that caregivers with different literacy levels may have interpreted the question differentially. The literacy burden of this question is considerably higher than the other items: the question contains 38 words (compared with fewer than 15 words for most of the other items), and asks the respondent to consider two dependent clauses (to the best of your knowledge and even for a moment), which add complexity and extend the recall period. In addition, people with low numeracy skills are more likely to employ "gist-based intuition" when processing such higher-burden information, whereas those with higher numeracy skills are more likely to process information "verbatim." 26 Therefore, caregivers with high literacy may have answered yes if they took their hand off of their child for even 1 second while on a bed or changing table, whereas those with low health literacy may have answered no for a similar situation.

The study population consisted of many families from traditionally under-represented minorities, including 50\% Hispanic families, and 27\% Black, Non-Hispanic families. In addition, $36 \%$ of caregivers identified Spanish as their primary language. This population has traditionally been at risk for poor health outcomes, ${ }^{27}$ and as expected, represented a high proportion of caregivers with low health literacy. While these results may not be generalizable to a broader population, it is important for pediatric providers to be cognizant of the lower health literacy of this population and their resultant propensity to be nonadherent with car seat placement and proper smoke detector checking.

Among the caregivers of 2-month-old infants in this study who own a firearm, $60 \%$ were not adhering to safe gun storage practices. Because of the small sample of caregivers who report owning a firearm, the analysis was underpowered to determine whether health literacy had 
any effect on adherence to firearm safety practices. Since this is such a pressing problem, however, we would recommend continued anticipatory guidance for caregivers of young infants regarding firearm safety using universal low-health literacy communication techniques.

This study has several limitations. Only $11 \%$ of caregivers were categorized as having low health literacy on the STOFHLA, despite 23\% reporting that they did not graduate from high school. This small distribution of low health literacy on the STOFHLA is similar to other studies, which reported low health literacy for between $2 \%$ and $22 \%$ of caregivers. ${ }^{9,28-30}$ In addition, many patients had a perfect STOFHLA score, resulting in a truncated distribution (i.e., the ceiling effect). ${ }^{9,31}$ The inability of the STOFHLA to quantify the higher end of a patient's literacy level may limit the statistical power to examine the relationship between literacy level and outcomes. $9,32-34$

This study relied on self-reported survey data that may not reflect actual injury prevention behaviors or injury outcomes, and can be susceptible to social desirability bias. Participants may have been more likely to give answers that they considered socially desirable (e.g., not willing to admit non-adherence with injury prevention behaviors). While there is no direct evidence that low health literacy is associated with providing more socially desirable responses, there is some evidence that social desirability bias may be associated with lower educational level. ${ }^{35}$ If individuals with lower education were more likely to give socially desirable responses, the result would be a differential misclassification, which would potentially bias the results away from the null hypothesis. The relatively low percentage of caregiver non-adherence in some of the outcome variables limited the number of variables included in the multivariate models, which may have resulted in residual confounding. Finally, this is a cross-sectional analysis, which can only draw inferences about association, not causality.

This study is the first to document significant associations between caregiver health literacy and injury prevention behaviors during the first months of life. This holds important implications for pediatric healthcare providers, as they provide anticipatory guidance to caregivers of infants, especially for training new parents on appropriate car seat use and discussing proper smoke detector checking. Furthermore, these results suggest the importance of continuing resident and pediatric provider education in low-health literacy communication. Previous studies have demonstrated that low-health literacy communication techniques and educational tools can improve health outcomes in children. ${ }^{33,36-38}$ These results suggest that careful attention to caregiver health literacy may be an important approach for future interventions that target childhood injury prevention.

\section{Acknowledgments}

Dr. Heerman is supported by a T-32 grant through Vanderbilt University (5T32HD060554-05). Dr. Yin is supported by a grant under the Robert Wood Johnson Foundation Physician Faculty Scholars Program and HRSA (12-191-1077 Academic Administrative Units in Primary Care). The study was also funded by NIH/National Center for Advancing Translational Sciences grants (NCATS) (UL1TR000445 and UL1RR025747) and the NYU CTIS (UL1 TR000038) The data management system REDCap was supported by a grant from NCATS/NIH (UL1 TR000445). We would also like to acknowledge Joanne Finkle, JD, RN, Marianna Garrettson, PhD, and Carol Runyan, $\mathrm{PhD}$ for their help in preparation of study questions, and our research assistants Evelyn Cruzatte, Maria Cerra, Sophie Ravanbakcht, Beth Throop, Lucila Bloise, and Danielle Quesada. 


\section{References}

1. CDC. WISQARS leading causes of death reports, national and regional, 1999-2010. Atlanta GA: CDC; 2010.

2. Agran PF, Anderson C, Winn D, Trent R, Walton-Haynes L, Thayer S. Rates of pediatric injuries by 3-month intervals for children 0 to 3 years of age. Pediatrics. 2003; 111(6 Pt 1):e683-92. [PubMed: 12777586]

3. Gielen AC, Wilson ME, McDonald EM, et al. Randomized trial of enhanced anticipatory guidance for injury prevention. Arch Pediatr Adolesc Med. 2001; 155(1):42-9. [PubMed: 11177061]

4. Gielen AC, McDonald EM, Wilson ME, et al. Effects of improved access to safety counseling, products, and home visits on parents' safety practices: results of a randomized trial. Arch Pediatr Adolesc Med. 2002; 156(1):33-40. [PubMed: 11772188]

5. USDHHS. Healthy people 2010. Washington DC: USDHHS; 2000. Conference ed

6. Nielsen-Bohlman, L. IOM (U.S.). Committee on Health Literacy. Health literacy: a prescription to end confusion. Washington DC: National Academies Press; 2004.

7. Berkman ND, Sheridan SL, Donahue KE, Halpern DJ, Crotty K. Low health literacy and health outcomes: an updated systematic review. Ann Intern Med. 2011; 155(2):97-107. [PubMed: 21768583]

8. Yin HS, Johnson M, Mendelsohn AL, Abrams MA, Sanders LM, Dreyer BP. The health literacy of parents in the U.S. : a nationally representative study. Pediatrics. 2009; 124 (3S ):S289-S298. [PubMed: 19861483]

9. Kumar D, Sanders L, Perrin EM, et al. Parental understanding of infant health information: health literacy, numeracy, and the Parental Health Literacy Activities Test (PHLAT). Acad Pediatr. 2010; 10(5):309-16. [PubMed: 20674532]

10. Bass JL. TIPP--the first ten years. Pediatrics. 1995; 95(2):274-5. [PubMed: 7838648]

11. Harris PA, Taylor R, Thielke R, Payne J, Gonzalez N, Conde JG. Research electronic data capture (REDCap)--a metadata-driven methodology and workflow process for providing translational research informatics support. J Biomed Inform. 2009; 42(2):377-81. [PubMed: 18929686]

12. Baker DW, Williams MV, Parker RM, Gazmararian JA, Nurss J. Development of a brief test to measure functional health literacy. Patient Educ Couns. 1999; 38(1):33-42. [PubMed: 14528569]

13. Berkman ND, Dewalt DA, Pignone MP, et al. Literacy and health outcomes. Evid Rep Technol Assess (Summ). 2004; 87:1-8. [PubMed: 15819598]

14. McCormack L, Bann C, Squiers L, et al. Measuring health literacy: a pilot study of a new skillsbased instrument. J Health Commun. 2010; 15 (2S):S51-S71.

15. Aguirre AC, Ebrahim N, Shea JA. Performance of the English and Spanish S-TOFHLA among publicly insured Medicaid and Medicare patients. Patient Educ Couns. 2005; 56(3):332-9. [PubMed: 15721976]

16. Laramee AS, Morris N, Littenberg B. Relationship of literacy and heart failure in adults with diabetes. BMC Health Serv Res. 2007; 7:98. [PubMed: 17605784]

17. Chew LD, Bradley KA, Flum DR, Cornia PB, Koepsell TD. The impact of low health literacy on surgical practice. Am J Surg. 2004; 188(3):250-3. [PubMed: 15450829]

18. Fang MC, Machtinger EL, Wang F, Schillinger D. Health literacy and anticoagulation-related outcomes among patients taking warfarin. J Gen Intern Med. 2006; 21(8):841-6. [PubMed: 16881944]

19. Garbers S, Chiasson MA. Inadequate functional health literacy in Spanish as a barrier to cervical cancer screening among immigrant Latinas in New York City. Prev Chronic Dis. 2004; 1(4):A07. [PubMed: 15670438]

20. Gerber BS, Cho YI, Arozullah AM, Lee SY. Racial differences in medication adherence: a crosssectional study of Medicare enrollees. Am J Geriatr Pharmacother. 2010; 8(2):136-45. [PubMed: 20439063]

21. Bowen ME, Cavanaugh KL, Wolff K, Davis D, Gregory B, Rothman RL. Numeracy and dietary intake in patients with type 2 diabetes. Diabetes Educ. 2013; 39(2):240-7. [PubMed: 23399688] 
22. DeWalt DA, Pignone MP. Reading is fundamental: the relationship between literacy and health. Arch Intern Med. 2005; 165(17):1943-4. [PubMed: 16186462]

23. Vick JW. Securing the safety of our most precious cargo: SAFE KIDS. Am J Matern Child Nurs. 2010; 35(1):52-7.

24. Moon RY, Oden RP, Grady KC. Back to Sleep: an educational intervention with women, infants, and children program clients. Pediatrics. 2004; 113(3 Pt 1):542-7. [PubMed: 14993547]

25. Coyne-Beasley T, McGee KS, Johnson RM, Bordley WC. The association of handgun ownership and storage practices with safety consciousness. Arch Pediatr Adolesc Med. 2002; 156(8):763-8. [PubMed: 12144365]

26. Nelson W, Reyna VF, Fagerlin A, Lipkus I, Peters E. Clinical implications of numeracy: theory and practice. Ann Behav Med. 2008; 35(3):261-74. [PubMed: 18677452]

27. Krieger N, Chen JT, Waterman PD, Rehkopf DH, Subramanian SV. Painting a truer picture of U.S. socioeconomic and racial/ethnic health inequalities: the Public Health Disparities Geocoding Project. Am J Public Health. 2005; 95(2):312-23. [PubMed: 15671470]

28. Ciampa PJ, White RO, Perrin EM, et al. The association of acculturation and health literacy, numeracy and health-related skills in Spanish-speaking caregivers of young children. J Immigr Minor Health. 2013; 15(3):492-8. [PubMed: 22481307]

29. Dominick GM, Dunsiger SI, Pekmezi DW, Marcus BH. Health literacy predicts change in physical activity self-efficacy among sedentary Latinas. J Immigr Minor Health. 2013; 15(3):533-9. [PubMed: 22733230]

30. Yin HS, Sanders LM, Rothman RL, et al. Assessment of health literacy and numeracy among Spanish-Speaking parents of young children: validation of the Spanish Parental Health Literacy Activities Test (PHLAT Spanish). Acad Pediatr. 2012; 12(1):68-74. [PubMed: 22056223]

31. Osborn CY, Cavanaugh K, Wallston KA, White RO, Rothman RL. Diabetes numeracy: an overlooked factor in understanding racial disparities in glycemic control. Diabetes Care. 2009; 32(9):1614-9. [PubMed: 19401443]

32. Janisse HC, Naar-King S, Ellis D. Brief report: parent's health literacy among high-risk adolescents with insulin dependent diabetes. J Pediatr Psychol. 2010; 35(4):436-40. [PubMed: 19755494]

33. Oettinger MD, Finkle JP, Esserman D, et al. Color-coding improves parental understanding of body mass index charting. Acad Pediatr. 2009; 9(5):330-8. [PubMed: 19679524]

34. Tran TP, Robinson LM, Keebler JR, Walker RA, Wadman MC. Health literacy among parents of pediatric patients. West J Emerg Med. 2008; 9(3):130-4. [PubMed: 19561727]

35. Hebert JR, Peterson KE, Hurley TG, et al. The effect of social desirability trait on self-reported dietary measures among multi-ethnic female health center employees. Ann Epidemiol. 2001; 11(6):417-27. [PubMed: 11454501]

36. Robinson LD Jr, Calmes DP, Bazargan M. The impact of literacy enhancement on asthma-related outcomes among underserved children. J Natl Med Assoc. 2008; 100(8):892-6. [PubMed: 18717138]

37. Yin HS, Mendelsohn AL, Fierman A, van Schaick L, Bazan IS, Dreyer BP. Use of a pictographic diagram to decrease parent dosing errors with infant acetaminophen: a health literacy perspective. Acad Pediatr. 2011; 11(1):50-7. [PubMed: 21272824]

38. Taveras EM, Gortmaker SL, Hohman KH, et al. Randomized controlled trial to improve primary care to prevent and manage childhood obesity: the High Five for Kids study. Arch Pediatr Adolesc Med. 2011; 165(8):714-22. [PubMed: 21464376] 




308 Declined (26.3\%)

865 Enrolled (73.7\%)

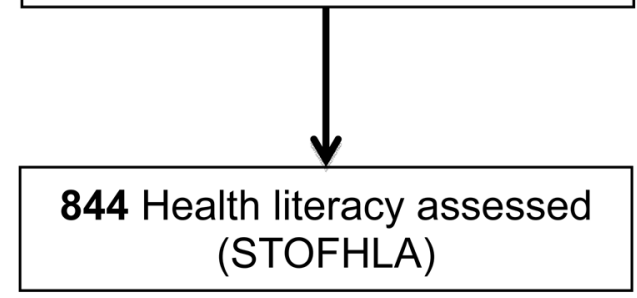

Figure 1.

Study enrollment

STOFHLA, Short Test of Functional Health Literacy in Adults 


\section{Table 1}

Injury prevention outcomes and associated survey questions

\begin{tabular}{|c|c|c|}
\hline $\begin{array}{l}\text { AAP injury prevention } \\
\text { recommendation } \\
\text { domain }\end{array}$ & Survey question & $\begin{array}{l}\text { Answers qualifying } \\
\text { as non-adherent }\end{array}$ \\
\hline \multirow{2}{*}{ Car seat position $a$} & Where do you place the car seat? (Front/back) & Front \\
\hline & Does your car seat face the front or back? & Front \\
\hline Car seat use & $\begin{array}{l}\text { In the last } 30 \text { days, how many times has [child's first name] been in a moving car or } \\
\text { vehicle without being strapped in the car seat even for a brief moment? }\end{array}$ & $\geq 1$ \\
\hline Sleeping safety & In the last 30 days, how many times has your child slept on his/her tummy? & $\geq 1$ \\
\hline Fire safety & Do you have a working smoke detector in your home? & No or I don't know \\
\hline Hot water heater & What is the temperature setting on your hot water heater? & $\begin{array}{l}>120^{\circ} \mathrm{F} \text { or I don't } \\
\text { know }\end{array}$ \\
\hline Fall prevention & $\begin{array}{l}\text { To the best of your knowledge, have you or anyone in your family ever left your child } \\
\text { alone on a table, sofa, bed, or other high place, even for a brief moment, while they } \\
\text { turned or stepped away? }\end{array}$ & Yes \\
\hline \multirow{4}{*}{ Firearm safety ${ }^{a}$} & Are your guns stored and locked? & No \\
\hline & Are your guns stored unloaded? & No \\
\hline & Are the bullets stored separately and locked? & No \\
\hline & $\begin{array}{l}\text { Do you keep even/at least one gun loaded and handy in case you need to protect your } \\
\text { family? }\end{array}$ & Yes \\
\hline
\end{tabular}

${ }^{a}$ These outcomes are based on answers to multiple questions. A non-adherent answer to any one of the questions classifies the respondent as nonadherent for that outcome.

AAP, American Academy of Pediatrics 
Table 2

Baseline characteristics and health literacy level of study participants

\begin{tabular}{|c|c|c|c|c|}
\hline \multirow[b]{2}{*}{ Child characteristics } & \multirow[b]{2}{*}{$\begin{array}{c}\text { Combined }(\mathrm{N}=844) \\
M(\mathrm{SD}) \text { or } n(\%)\end{array}$} & \multicolumn{2}{|c|}{ Health literacy } & \multirow[b]{2}{*}{$p$-value } \\
\hline & & $\begin{array}{c}\text { Low }(n=93) \\
\text { M (SD) or } n(\%)\end{array}$ & $\begin{array}{l}\text { Adequate }(n=751) \\
\text { M (SD) or } n(\%)\end{array}$ & \\
\hline Child age (Months) & $2.1(0.4)$ & $2.2(0.4)$ & $2.1(0.4)$ & 0.43 \\
\hline Child gender (Female) & $436(52 \%)$ & $49(53 \%)$ & $387(52 \%)$ & 0.83 \\
\hline Child WIC status (None) & $124(15 \%)$ & $9(10 \%)$ & $115(15 \%)$ & 0.14 \\
\hline \multicolumn{5}{|l|}{ Caregiver Characteristics } \\
\hline Caregiver age (Years) & $27.6(6.2)$ & $29.7(7.3)$ & $27.3(5.8)$ & 0.002 \\
\hline \multicolumn{5}{|l|}{ Relationship to child } \\
\hline Mother & $809(96 \%)$ & $97(94 \%)$ & $722(96 \%)$ & \multirow{3}{*}{0.15} \\
\hline Father & $33(4 \%)$ & $5(5 \%)$ & $28(4 \%)$ & \\
\hline Other & $2(0.2 \%)$ & $1(1 \%)$ & $1(0.1 \%)$ & \\
\hline Caregiver gender, female & $808(96 \%)$ & $87(94 \%)$ & $721(96 \%)$ & 0.3 \\
\hline \multicolumn{5}{|l|}{ Caregiver race/ethnicity } \\
\hline Hispanic & $420(50 \%)$ & $61(66 \%)$ & $359(48 \%)$ & \multirow{3}{*}{$<0.001$} \\
\hline Non-Hispanic, White & $151(18 \%)$ & $3(3 \%)$ & $148(20 \%)$ & \\
\hline Non-Hispanic, Other & $273(32 \%)$ & $29(31 \%)$ & $244(32 \%)$ & \\
\hline Caregiver language, Spanish & $298(36 \%)$ & $55(60 \%)$ & $243(32 \%)$ & $<0.001$ \\
\hline \multicolumn{5}{|l|}{ Caregiver education } \\
\hline Less than HS & $221(26 \%)$ & $50(54 \%)$ & $171(23 \%)$ & \multirow{4}{*}{$<0.001$} \\
\hline HS graduate/equivalent & $273(33 \%)$ & $26(28 \%)$ & $247(33 \%)$ & \\
\hline Some college & $199(24 \%)$ & $8(9 \%)$ & $191(26 \%)$ & \\
\hline College or greater & $148(18 \%)$ & $9(10 \%)$ & $139(19 \%)$ & \\
\hline Caregiver health literacy score (STOFHLA) & $31.4(7.8)$ & $11.3(7.1)$ & $33.8(2.6)$ & $<0.001$ \\
\hline Caregiver health literacy (STOFHLA) & & & & NA \\
\hline Inadequate & $66(8 \%)$ & & & \\
\hline Marginal & $27(3 \%)$ & & & \\
\hline Adequate & $751(89 \%)$ & & & \\
\hline \multicolumn{5}{|l|}{ Household characteristics } \\
\hline \multicolumn{5}{|l|}{ Household income } \\
\hline$<\$ 10,000$ & $262(32 \%)$ & $53(61 \%)$ & $209(29 \%)$ & \multirow{4}{*}{$<0.001$} \\
\hline$\$ 10,000-\$ 19,999$ & $224(28 \%)$ & $22(25 \%)$ & $202(28 \%)$ & \\
\hline$\$ 20,000-\$ 39,999$ & $198(24 \%)$ & $11(13 \%)$ & $187(26 \%)$ & \\
\hline $2 \$ 40,000$ & $128(16 \%)$ & $1(1 \%)$ & $127(18 \%)$ & \\
\hline
\end{tabular}




\begin{tabular}{|lcccc|}
\hline & \multicolumn{4}{c|}{ Health literacy } \\
Child characteristics & $\begin{array}{c}\text { Combined (N=844) } \\
\text { M (SD) or } \boldsymbol{n}(\boldsymbol{\%})\end{array}$ & $\begin{array}{c}\text { Low }(\boldsymbol{n}=\mathbf{9 3}) \\
\text { M(SD) or } \boldsymbol{n} \text { (\%) }\end{array}$ & $\begin{array}{c}\text { Adequate }(\boldsymbol{n}=\mathbf{7 5 1}) \\
\text { M (SD) or } \boldsymbol{n} \text { (\%) }\end{array}$ & $\boldsymbol{p}$-value \\
\hline Number of children in home & & & & \\
1 & $336(40 \%)$ & $39(42 \%)$ & $297(40 \%)$ & \\
2 & $252(30 \%)$ & $26(28 \%)$ & $226(30 \%)$ & 0.99 \\
3 & $142(17 \%)$ & $15(16 \%)$ & $127(17 \%)$ & \\
4 or More & $111(13 \%)$ & $11(12 \%)$ & $98(13 \%$ & \\
\hline Site & & & & \\
NYU & $228(27 \%)$ & $41(44 \%)$ & $187(25 \%)$ & \\
Miami & $135(16 \%)$ & $25(27 \%)$ & $110(15 \%)$ & $<$ \\
UNC Chapel Hill & $253(30 \%)$ & $18(19 \%)$ & $235(31 \%)$ & \\
Vanderbilt & $228(27 \%)$ & $9(10 \%)$ & $219(30 \%)$ & \\
\hline
\end{tabular}

Note: Boldface indicates statistically significant $p$-values $(<0.05)$.

*

p-values were obtained using Pearson chi-square and Kruskal-Wallis tests for categorical and ordinal variables, respectively.

Abbreviations: HS, high school; NYU, New York University; STOFHLA, Short Test of Functional Health Literacy for Adults; UNC, University of North Carolina; WIC, Women Infants and Children 


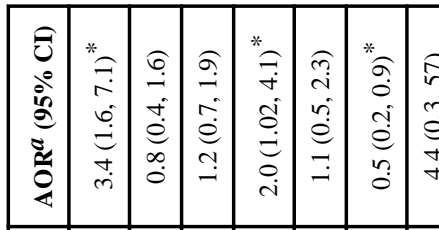

ยิ

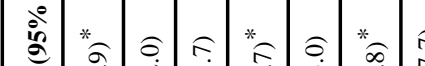

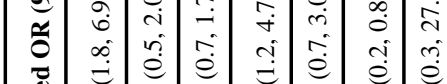



可

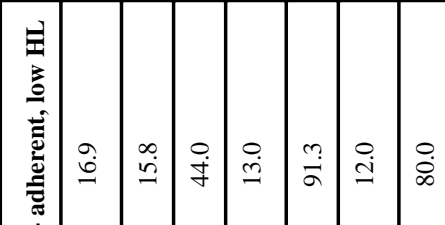

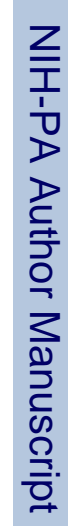

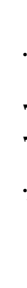

$\frac{\sqrt[n]{0}}{\sqrt{3}}$

保

目

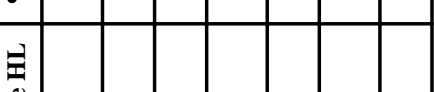

国

产

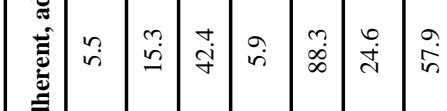

密

言



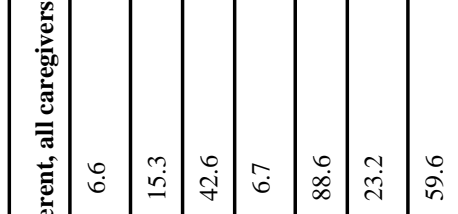

胥

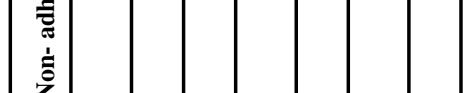



Am J Prev Med. Author manuscript; available in PMC 2015 May 01. 